\title{
Elaboration of Normative Values of Visual Evoked Potentials in the Neurophysiological Exploration Laboratory of the Neurology Department at Fann Teaching Hospital in 2020
}

\section{Nagasaki Saurel Ralmach ${ }^{1}$, Seck Lala Bouna ${ }^{1}$, Dinga Boudzoumba Stane Steeven ${ }^{1}$, Mualaba Célèbre ${ }^{2 *}$, Mpung Mansoy Halladain ${ }^{1}$, Katende Mbuyi Thierry ${ }^{1}$, Ndiaye Moustapha ${ }^{1}$ and Diop Amadou Gallo ${ }^{1}$}

${ }^{1}$ Neurology Department at Fann Teaching Hospital, Senegal

${ }^{2}$ Neurosurgery Department at Fann Teaching Hospital, Senegal

*Corresponding Author: Mualaba Célèbre, Neurosurgery Department at Fann

Teaching Hospital, Senegal.

DOI: 10.31080/ASNE.2021.04.0464
Received: July 30, 2021

Published: November 29, 2021

(C) All rights are reserved by Nagasaki Saurel Ralmach., et al.

\begin{abstract}
Introduction: Visual evoked potential (VEP) is the electrical response of the occipital cortex that is elicited by visual stimulation. They study macular and perimacular functioning as well as the conduction of visual pathways. They therefore contribute to the diagnosis of several diseases of the central nervous system such as Devic's optic neuromyelitis and multiple sclerosis. Their standards vary from one laboratory to another due to the difference in conditions and stimulation materials. The objective of this study is to present the results of our laboratory comparative to others laboratories.
\end{abstract}

Materials and Methods: This was a prospective cross-sectional study that consisted in realizing the VEP of checkerboard at 60 minutes of arc in 50 people in apparent good health and free from eye disorders distributed equally between men and women and in the age group under 40 and 40 and over.

Results: P100 latency was $97.86 \pm 4.37 \mathrm{msec}$ in the right eye versus $97.92 \pm 4.10 \mathrm{msec}$ in the left eye in men and $94.63 \pm 5.08 \mathrm{msec}$ in the right eye versus $94.88 \pm 4.87 \mathrm{msec}$ in the left eye in women. Overall, it was $96.25 \pm 4.97 \mathrm{msec}$ in the right eye compared to 96.40 $\pm 4.71 \mathrm{msec}$ in the left eye. The amplitude of P100 was $6.61 \pm 3.28 \mu \mathrm{V}$ on the right and $6.51 \pm 3.10 \mu \mathrm{V}$ overall. The amplitudes were greater and the latencies shorter in women.

VEP vary significantly depending on gender, height and weight. But there was no significant change in age and body mass index.

Conclusion: The normative values of the VEP in our study were close to those found in the literature. They vary with respect to sex and anthropometric parameters.

Keywords: Normative Values; VEP; Senegal

\section{Introduction}

Visual evoked potential (VEP) is the electrical response of the occipital cortex that is elicited by visual stimulation [1]. VEP re- sult from the recording of variations in potentials generated by the bio-ionic activity of the occipital cortex following a visual stimulus

[2]. They study macular and perimacular functioning as well as the 
conduction of visual pathways [3-5]. They result from the amplification of signals from the photopic system located over the entire macular surface (flash VEP or VEP Onset-Offset) or in different macular sectors (checkered VEP) and their conduction along the visual pathways [3].

They therefore contribute to the diagnosis of several diseases of the central nervous system such as neuromyelitis optic and multiple sclerosis. The interpretation of their results must take into account the operating state of the overall photopic system (flash ERG) but above all localized (multifocal ERG and Pattern - ERG [3].

VEP are obtained by stimulation of the retina, either by flashes or by inversion of checkerboards. Recording electrodes placed on the scalp opposite the occipital lobe obtain the evoked response. A unilateral visual pathway defect can be obscured if both eyes are stimulated at the same time. Thus, monocular stimulation is recommended [6].

VEP can be used as an objective, non-invasive method of assessing the visual system in children and uncooperative patients [7].

Two stimulation methods are commonly used: flash stimulation and checkerboard inversion stimulation $[5,8]$. Stimulation by checkerboard inversion is preferred because it exhibits less variability in shape and maximum latency both in an individual and in the general population, except in certain situations such as in children $[5,6]$.

Their values vary from one laboratory to another given the difference in stimulation factors (lumination, field size, etc.), but also according to age, sex, size, acuity visual and pupillary size $[3,4,7,8]$. The normal response includes a negative wave (N75) then a positive wave (P100) followed by a negative deflection (N145) [8]. The parameters of the checkered VEPs include the latencies of the N75, P100, N145 responses and the amplitudes N75 and P100 [4].

The International Society for Clinical Electrophysiology of Vision recommends that each clinical neurophysiology laboratory should have its own normative values for visual evoked potentials $[4,5]$. Thus, we deemed it appropriate to conduct this study, the objective of which is to establish the normative values of checkered VEPs in the neurophysiological exploration laboratory of the Neu- rology department of Fann teaching Hospital and more specifically to describe the characteristics of the population. And to determine the effect of age, gender, height, weight and BMI on VEP.

\section{Population, Materials and Methods}

Study framework

Our study took place in the neurophysiological exploration laboratory at Fann Teaching Hospital. It is the reference center for neurophysiological explorations for all of Senegal, divided into two parts, namely an EEG block with 3 recording machines and 4 interpretation stations; and an EMG-PE block with 2 EMG devices and an EPI monitor. This laboratory is run by 8 neurophysiologists and 3 EEG technicians and 3 EMG technicians.

\section{Type of study}

It was a cross-sectional, prospective, descriptive and analytical study.

\section{Study period}

This study took place from August 05 to September 05, 2020, a period of one month.

\section{Study population}

We performed the checkered VPEs on fifty (50) people in apparent good health and free from any visual disturbance.

\section{Inclusion criteria}

We included in this study apparently healthy subjects of any gender, aged 19 to 56 years.

\section{Non-inclusion criteria}

Ametropic subjects (myopic and hyperopic) as well as those with other ophthalmic diseases such as cataracts were not included in our study.

\section{Study method}

We systematically recruited 50 subjects in apparent good health and free of eye disorders, divided into 25 subjects of each sex divided into the age groups of less than 40 years and 40 years and over to take into account variations linked to sex and age. A sheet has been developed to facilitate data collection. The data were recorded on Excel software. 
Elaboration of Normative Values of Visual Evoked Potentials in the Neurophysiological Exploration Laboratory of the Neurology Department at Fann Teaching Hospital in 2020

\section{Registration method}

The parameters studied were the checkerboard latency of the N75, P100 and N145 waves and the amplitude of the P100 wave.

\section{Equipment used}

We used an ENMG Micromed device for recording VEPs (Figure 1) and an VEP monitor displaying a checkerboard alternating with a homogeneous light field for their genesis (Figure 2).

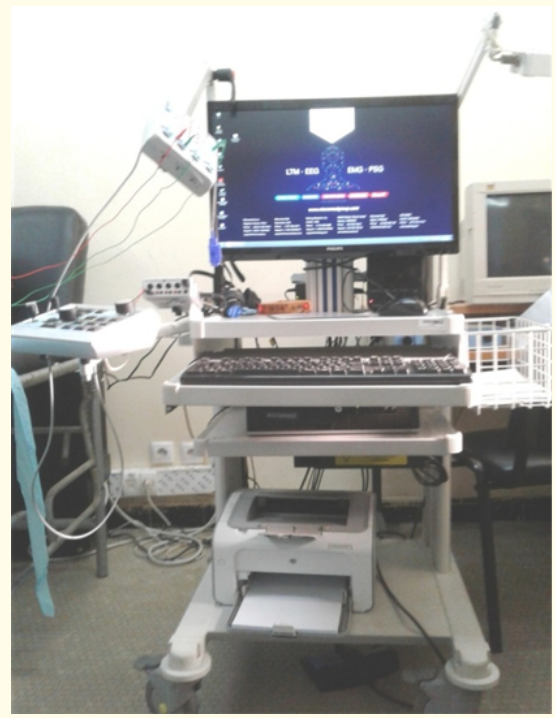

Figure 1: Micromed EMG device.

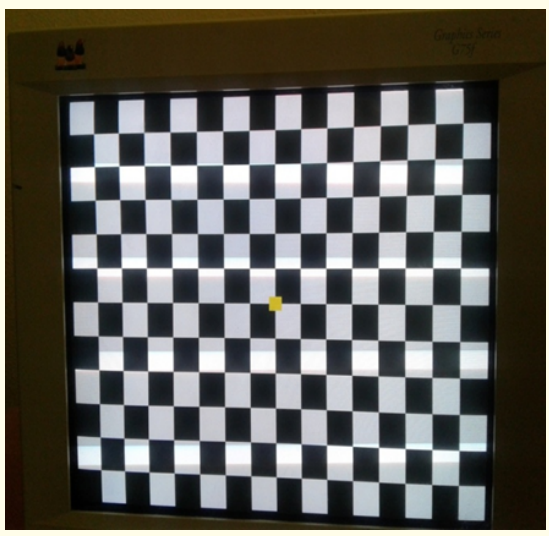

Figure 2: VEP monitor displaying the alternate black to white then white to black checkerboards with a central yellow point, zone of gaze fixation by the subject.
Needle electrodes were used (Figure 3). These subcutaneous electrodes were placed at the scalp. The active electrode was placed in $\mathrm{Oz}$. The reference in $\mathrm{CZ}$, according to the international 10/20 system (Figure 4). The earth was placed on the forearm.

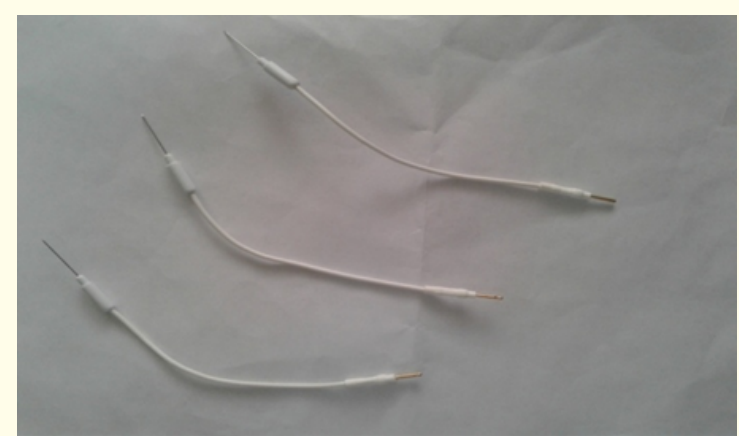

Figure 3: Needle électrodes.

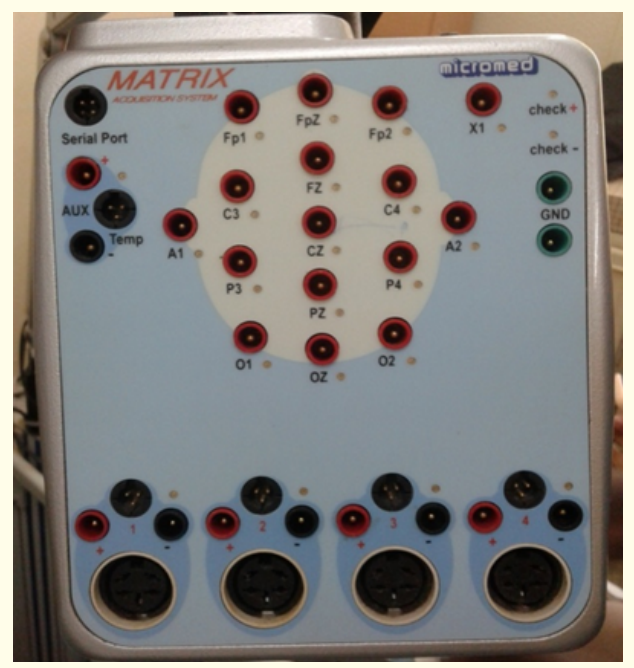

Figure 4: EMG/PE amplifier using the international $10 / 20$ system.

These needle electrodes were connected to the ENMG Micromed device by connection cables (Figure 5) via an EMG/PE amplifier according to the international $10 / 20$ system (Figure 6 ).

\section{Registration procedure}

The recording was made in a dark and quiet room. 


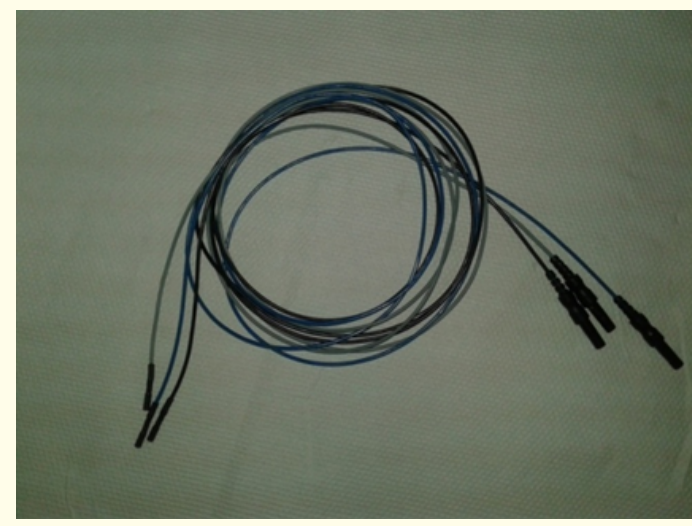

Figure 5: Connection cable for needle electrodes.

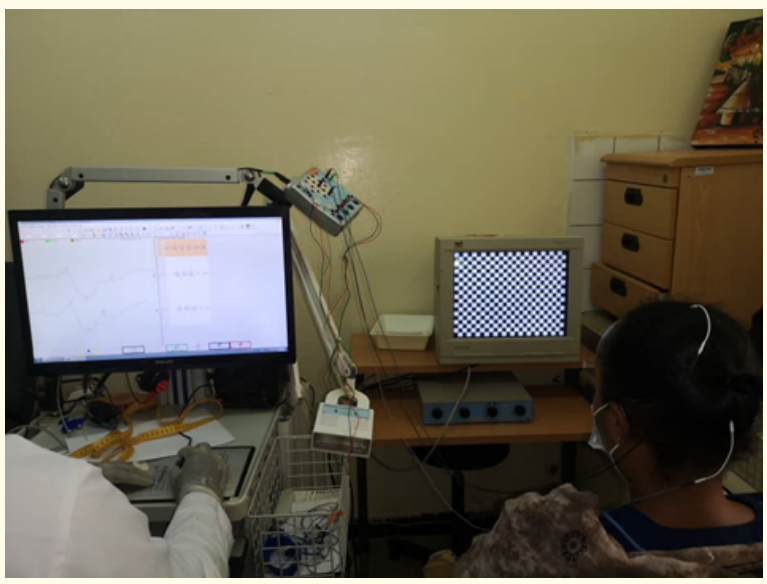

Figure 6: Installation of the subject.

The subject seated $90 \mathrm{~cm}$ from the checkerboard monitor is asked to gaze at the center of the screen or displaying a yellow dot.

An alternating checkerboard (black to white and white to black) performed the stimulation. The subject was seated at a fixed distance of $90 \mathrm{~cm}$ from the screen and was asked to stare at the center of the screen (a yellow dot) figures 2 and 6. Monocular full-field stimulation was administered to both eyes separately afterwards. Successive occultation of one then the other eye using a compress, which was fixed by an adhesive tape of the plaster type. A $200 \mathrm{msec}$ sweep length was performed and 100 responses were averaged. To ensure the reproducibility of the values and the shape of the waves, two curves were averaged.

\section{Study variables}

The variables studied were age, sex, height, weight, body mass index, checkerboard latency at 60 min of arc of the N75, P100 and N145 waves and the amplitude of the P100 wave.

\section{Results analysis plan}

We used SPSS version 22 software for statistical analyzes. The confidence interval was calculated at $95 \%$ and the significance level retained at 0.05 . Pearson's correlation tests, Chi-square test, t-student, and Anova test were used for correlation and comparison of the data.

\section{Ethical considerations}

We obtained informed consent from subjects to interview, examine, and perform EPIs for them. Anonymity was observed.

\section{Results}

\section{Socio-demographic characteristics}

Our study concerned a population of 50 people with an average age of $33.48 \pm 8.81$ years with the extremes ranging from 19 to 56 years.

This population was made up of 25 men and 25 women divided into sections of 36 subjects under 40 (17 women and 19 men) and 14 aged 40 and over (8women and six men).

The weight was $70.37 \pm 11.15 \mathrm{~kg}$ with the extremes ranging from 56 to $110 \mathrm{~kg}$. The average height was $172.06 \pm 9.40 \mathrm{~cm}$. The BMI was $23.81 \pm 3.54 \mathrm{Kg} / \mathrm{m}^{2}$ with extremes ranging from 18.87 to $34.33 \mathrm{Kg} / \mathrm{m}^{2}$.

\begin{tabular}{|c|c|c|c|c|}
\hline & Age & Weight & CUT & IMC \\
\hline $\mathrm{N}$ & 50 & 50 & 50 & 50 \\
\hline Average & 33,48 & 70,37 & 172,06 & 23,81 \\
\hline Median & 31 & 68,50 & 170 & 23,03 \\
\hline Standard deviation & 8,81 & 11,15 & 9,40 & 3,54 \\
\hline Minimum & 19 & 56 & 155 & 18,87 \\
\hline Maximum & 56 & 110 & 194 & 34,33 \\
\hline
\end{tabular}

Table 1: Anthropometric parameters. 
Elaboration of Normative Values of Visual Evoked Potentials in the Neurophysiological Exploration Laboratory of the Neurology Department at Fann Teaching Hospital in 2020

\section{VEPs parameters}

VEPs were represented by a curve formed by a negative wave N75 followed by a large positive wave P100 and a negative wave N145. See figure 7.

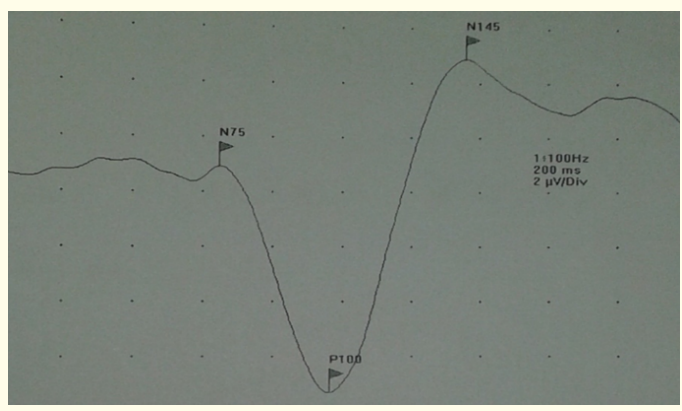

Figure 7: VEPs curve.

\section{P100 latency}

The latency of P100 was $97.86 \pm 4.37 \mathrm{~ms}$ in the right eye versus $97.92 \pm 4.10 \mathrm{~ms}$ in the left eye in men and $94.63 \pm 5.08 \mathrm{~ms}$ in the right eye versus $94.88 \pm 4.87 \mathrm{~ms}$ in the left eye in women. Overall, it was $96.25 \pm 4.97 \mathrm{msec}$ in the right eye compared to $96.40 \pm 4.71$ msec in the left eye. See tables 2, 3 and 4.

\section{Amplitude of P100}

The amplitude of P100 was $5.66 \pm 2.83$ in the right eye versus $5.52 \pm 2.43$ in the left eye in men and $7.57 \pm 3.47$ in the right eye versus $7,49 \pm 3.42$ in the left eye in women. Overall, it was $6.61 \pm$ 3.28 in the right eye compared to $6.51 \pm 3.10$ in the left eye.

Correlations and comparisons

Variations in relation to sex

\begin{tabular}{|c|c|c|c|c|c|c|c|c|c|c|c|c|}
\hline & \multicolumn{4}{|c|}{$\begin{array}{c}\text { Right eye } \\
\text { (N = 50) }\end{array}$} & \multicolumn{5}{c|}{ Left eye } & \multicolumn{3}{c|}{ Difference: Right eye- Left eye } \\
\hline & \multicolumn{3}{|c|}{ Latencies } & Amp & \multicolumn{3}{c|}{ Latencies } & Amp & \multicolumn{3}{c|}{ Latencies } & Amp \\
\hline & N75 & P100 & N145 & P100 & N75 & P100 & N145 & P100 & N75 & P100 & N145 & P100 \\
\hline Average & 67,98 & 96,25 & 133 & 6,61 & 68,08 & 96,40 & 133,63 & 6,51 & $-0,1$ & $-0,15$ & $-0,63$ & 0,1 \\
\hline Median & 68,12 & 96,56 & 133,30 & 5,64 & 68,61 & 96,68 & 130,98 & 5,74 & $-0,49$ & $-0,12$ & 2,32 & $-0,1$ \\
\hline $\begin{array}{c}\text { Standard } \\
\text { deviation }\end{array}$ & 4,75 & 4,97 & 12,36 & 3,28 & 4,93 & 4,71 & 13,17 & 3,10 & $-0,18$ & 0,26 & $-0,81$ & 0,18 \\
\hline Minimum & 57,13 & 84,96 & 110,35 & 1,78 & 53,47 & 84,72 & 110,11 & 1,57 & & & & \\
\hline Maximum & 80,57 & 106,93 & 158,45 & 17,68 & 79,59 & 106,93 & 161,62 & 15,15 & $\mathbf{N 7 5}$ & & & \\
\hline
\end{tabular}

Table 2: PEV in 50 apparently healthy subjects.

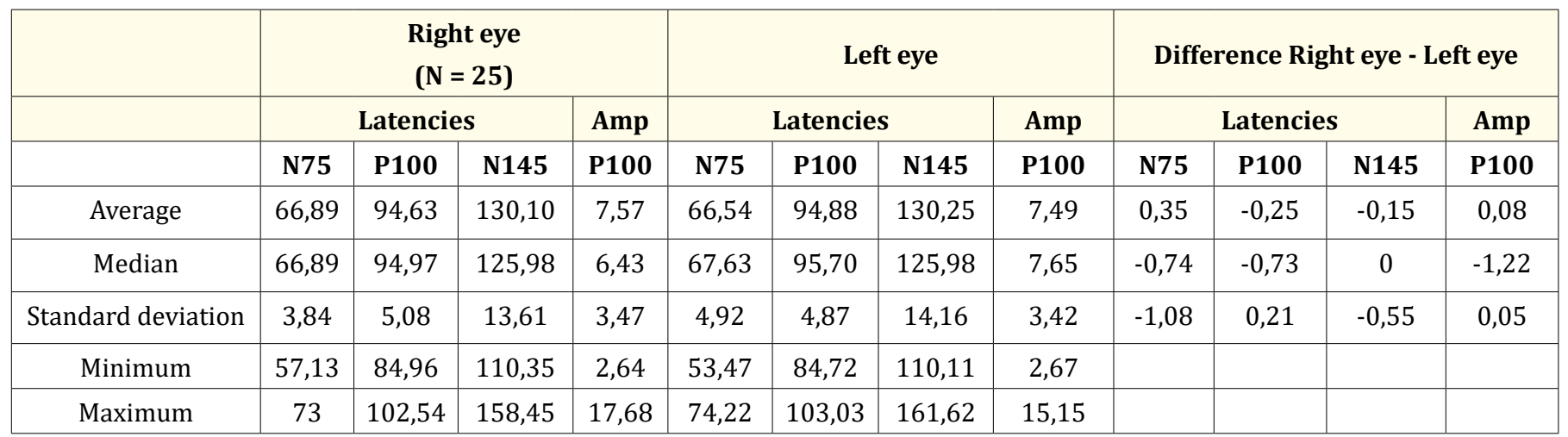

Table 3: VEP in female subjects. 
Elaboration of Normative Values of Visual Evoked Potentials in the Neurophysiological Exploration Laboratory of the Neurology Department at Fann Teaching Hospital in 2020

\begin{tabular}{|c|c|c|c|c|c|c|c|c|c|c|c|c|}
\hline & \multicolumn{4}{|c|}{$\begin{array}{c}\text { Right eye } \\
(N=25)\end{array}$} & \multicolumn{4}{|c|}{$\begin{array}{l}\text { Left eye } \\
(N=25)\end{array}$} & \multicolumn{4}{|c|}{ Difference RE - LE } \\
\hline & \multicolumn{3}{|c|}{ Latencies } & \multirow{2}{*}{\begin{tabular}{|c|} 
Amp \\
P100
\end{tabular}} & \multicolumn{3}{|c|}{ Latencies } & \multirow{2}{*}{$\begin{array}{l}\text { Amp } \\
\text { P100 }\end{array}$} & \multicolumn{3}{|c|}{ Latencies } & \multirow{2}{*}{$\begin{array}{l}\text { Amp } \\
\text { P100 }\end{array}$} \\
\hline & N75 & P100 & N145 & & N75 & P100 & N145 & & N75 & P100 & N145 & \\
\hline Average & 69,06 & 97,86 & 135,91 & 5,66 & 69,63 & 97,93 & 137,01 & 5,52 & $-0,57$ & $-0,07$ & $-1,10$ & 0,14 \\
\hline Median & 69,58 & 98,14 & 134,52 & 5,11 & 69,09 & 97,90 & 135,01 & 5,04 & 0,49 & 0,24 & $-0,49$ & 0,07 \\
\hline Standard deviation & 5,38 & 4,37 & 10,44 & 2,83 & 4,52 & 4,10 & 11,39 & 2,43 & 0,85 & 0,27 & $-0,95$ & 0,40 \\
\hline Minimum & 57,62 & 90,82 & 115,97 & 1,78 & 61,77 & 90,33 & 119,87 & 1,57 & & & & \\
\hline Maximum & 80,57 & 106,93 & 157,47 & 12,22 & 79,59 & 106,93 & 160,4 & 10,82 & & & & \\
\hline
\end{tabular}

Table 4: VEP in males.

The difference in P100 latencies between the 2 sexes was statistically significant with $P$ value of 0.020 on the right and 0.021 on the left. Indeed, the latency of P100 decreases in women $(\mathrm{t}=-2.39$ on the left and -2.40 on the right). This difference was also significant for amplitudes of 100 with a $P$ value of 0.037 in the right eye and 0.023 in the left eye. Indeed, the amplitude of P100 increases in women $(\mathrm{t}=2.142$ on the right and 2.349 on the left).

Variation of P100 parameters between right and left eye

The amplitudes and latencies of P100 were insignificantly greater in the right eye compared to the left eye $(t=0.166 ; \mathrm{P}=0.86)$. The latencies and amplitudes of $\mathrm{P} 100$ on the right were correlated with those on the left $(\mathrm{P}=0.000)$.

Variations in P100 parameters as a function of age and BMI
In subjects under 40 years of age, the P100 latency was $96.43 \pm$ $5.07 \mathrm{~ms}$ on the right versus $96.68 \pm 4.98 \mathrm{~ms}$ on the left; the amplitude was $6.42 \pm 2.86 \mu \mathrm{V}$ on the right versus $6.34 \pm 2.74 \mu \mathrm{V}$ on the left. See table 5 .

In subjects 40 years of age and over, they were $95.79 \pm 4.84 \mathrm{~ms}$ on the right versus $95.69 \pm 4.02 \mathrm{~ms}$ on the left and $7.11 \pm 4.25 \mu \mathrm{V}$ on the right versus $6.95 \pm 3.97 \mu \mathrm{V}$ on the left. See table 6 .

The latencies $(\mathrm{t}=0.41$ on the right and 0.72 on the left; $\mathrm{P}=0.68$ on the right and 0.47 on the left) and the amplitudes $(\mathrm{t}=-0.56$ on the right and -0.53 on the left; $\mathrm{P}=0.57$ on the right and 0.60 on the left) of P100 do not change significantly with age. Thus, the difference in P100 parameters between subjects younger than and older than 40 was not statically significant. The amplitude and latency of P100 therefore do not vary significantly with age.

\begin{tabular}{|c|c|c|c|c|c|c|c|c|c|c|c|c|}
\hline & \multicolumn{4}{|c|}{$\begin{array}{c}\text { Right eye } \\
(N=36)\end{array}$} & \multicolumn{4}{|c|}{ Left eye $(N=36)$} & \multicolumn{4}{|c|}{$\begin{array}{c}\text { Difference Right eye } \\
\text { - Left eye }\end{array}$} \\
\hline & \multicolumn{3}{|c|}{ Latencies } & $\begin{array}{l}\text { Amp } \\
\text { P100 }\end{array}$ & \multicolumn{3}{|c|}{ Latencies } & $\begin{array}{l}\text { Amp } \\
\text { P100 }\end{array}$ & \multicolumn{3}{|c|}{ Latencies } & $\begin{array}{l}\text { Amp } \\
\text { P100 }\end{array}$ \\
\hline Average & 67,71 & 96,43 & 135,15 & 6,42 & 67,94 & 96,68 & 136,24 & 6,34 & $-0,23$ & $-0,25$ & $-1,09$ & 0,08 \\
\hline $\begin{array}{l}\text { Standard de- } \\
\text { viation }\end{array}$ & 5,14 & 5,07 & 13,11 & 2,86 & 5,19 & 4,98 & 13,66 & 2,74 & $-0,05$ & 0,09 & $-0,55$ & 0,12 \\
\hline Minimum & 57,13 & 84,96 & 110,35 & 2,62 & 53,47 & 84,72 & 115,48 & 2,46 & & & & \\
\hline Maximum & 80,57 & 106,93 & 158,45 & 12,68 & 79,59 & 106,93 & 161,62 & 14,61 & & & & \\
\hline
\end{tabular}

Table 5: VEP in subjects under 40 years of age. 
Elaboration of Normative Values of Visual Evoked Potentials in the Neurophysiological Exploration Laboratory of the Neurology Department at Fann Teaching Hospital in 2020

\begin{tabular}{|c|c|c|c|c|c|c|c|c|c|c|c|c|}
\hline \multirow[b]{3}{*}{ N75 } & \multicolumn{4}{|c|}{ Right eyen $(\mathrm{N}=14)$} & \multicolumn{4}{|c|}{ Left eye $(N=14)$} & \multicolumn{4}{|c|}{$\begin{array}{c}\text { Difference Right eye } \\
\text { - Left eye }\end{array}$} \\
\hline & \multicolumn{3}{|c|}{ Latences } & \multirow{2}{*}{$\begin{array}{l}\text { Amp } \\
\text { N75 }\end{array}$} & \multicolumn{3}{|c|}{ Latences } & \multirow{2}{*}{$\begin{array}{l}\text { Amp } \\
\text { N75 }\end{array}$} & \multicolumn{3}{|c|}{ Latences } & \multirow[t]{2}{*}{ Amp } \\
\hline & P100 & N145 & P100 & & P100 & N145 & P100 & & P100 & N145 & P100 & \\
\hline Moyenne & 68,67 & 95,79 & 127,49 & 7,11 & 68,44 & 95,69 & 126,93 & 6,95 & 0,23 & 0,1 & 0,56 & 0,16 \\
\hline Median & 69,33 & 95,82 & 126,83 & 6,30 & 68,85 & 96,80 & 125,85 & 6,16 & $-0,65$ & $-0,98$ & 0,98 & 0,14 \\
\hline Ecart-type & 3,66 & 4,84 & 8,24 & 4,25 & 4,31 & 4,02 & 9,17 & 3,97 & $-0,65$ & 0,82 & $-0,93$ & 0,28 \\
\hline Minimum & 63,23 & 87,16 & 112,06 & 1,78 & 61,04 & 89,11 & 110,11 & 1,57 & & & & \\
\hline Maximum & 76,17 & 103,27 & 140,63 & 17,68 & 77,64 & 101,32 & 145,26 & 15,15 & & & & \\
\hline
\end{tabular}

Table 6: VEP in subjects 40 years of age and over.

BMI increases significantly with age (Pearson's coefficient at +0.319 and P-value at 0.024 ), but the parameters of the P100 wave do not vary with age or with respect to BMI.

Variation of P100 as a function of height and weight

The amplitudes of P100 do not vary significantly with height ( $p$ $=0.368$ on the right and 0.329 on the left) but the latencies increase significantly ( $p=0.000$ on the right and 0.003 on the left).

Likewise, for the weight, the amplitudes do not vary significantly ( $p=0.998$ on the right and 0.003 on the left) but the latencies increase significantly ( $p=0.021$ on the right and 0.009 on the left).

\section{Discussion}

Examination of VEP is an important procedure for assessing visual function and is very sensitive for assessing damage to the optic nerve and anterior chiasma [6].

\section{Socio-demographic characteristics}

Several studies have been carried out in young subjects with an equal proportion in both sexes [8-10] to take account of variations by sex. In Morocco, a study was carried out on around 20 adults aged under and over 40 to take into account age-related variations [11]. Bugeme in Senegal worked on 40 subjects under and over 40 years old equally between women and men [10].

We worked on 50 subjects under and over 40 equally in both sexes to account for variations in age and sex. Several authors $[8,9]$ have considered this number and this distribution.
The average age in our study was 33.48 years with the extremes ranging from 19 to 56 years. This age is in agreement with Bugeme who obtained 34.5 years with the extremes ranging from 18 to 50 years [10]. Patricia de Freitas Dotto in Brazil observed the older ages with a mean age of $40.4 \pm 13.7$ years [9]. Its study population, made up of university workers as well as students, can explain this. Monireh Mahjoob [4] in Iran and Ruby Sharma [8] in India observed the lower ages with respectively 18 and 22.5 years. This inferiority can be explained by their study population, which was essentially made up of students.

\section{VEP parameters}

\section{P100 latency}

In the literature it has been shown that latencies increase with age [14].

The results in our study were similar to those of Patricia de Freitas Dotto with a latency of P100 of $96.1 \pm 4.2 \mathrm{~ms}$ in women and 97.7 $\pm 4.2 \mathrm{~ms}$ in men [9].

Longer latencies were observed by Bugeme [10] in Senegal and even more in Morocco [11] with respectively $100.91 \mathrm{~ms}$ on the right and $99.98 \mathrm{~ms}$ on the left in women and $109.5 \mathrm{~ms}$ on the right and $108.7 \mathrm{~ms}$ to the left. This difference may be related to the difference in the material and methods of stimulation.

Short latencies were found by Shibasaki H and Kuroiwa Y [12] with $92.5 \pm 4.44 \mathrm{~ms}$, by Tandon OP and Sharma KN [13] with 95.37 $\pm 6.85 \mathrm{~ms}$ for men and $91.07 \pm 49 \mathrm{~ms}$ for women and by Ruby Sharma with $88.31 \pm 8.799$ in women and $93.214 \pm 10.656$ in men on 
Elaboration of Normative Values of Visual Evoked Potentials in the Neurophysiological Exploration Laboratory of the Neurology Department at Fann Teaching Hospital in 2020

the left; $88.788 \pm 8.984$ in women and $93.41 \pm 10.528$ in men on the right [8].

In these studies, the latencies of P100 were shorter compared to our study. This difference can be explained by the age, which was younger in these studies.

\section{Amplitude of P100}

Our amplitudes are similar to those found in the literature [8]. However, the larger amplitudes were observed by Monireh Mahjoob [4] with an amplitude of P100 at $15.04 \pm 6.26 \mu \mathrm{V}$.

Variations in P100 wave parameters

Variation of P100 according to sex

The latencies of N75, P100 and N145 were longer and the amplitudes shorter in men while the amplitudes were greater and the latencies shorter in women statistically significantly. These results are in agreement with the majority of studies $[8,9,12,13,15,16]$. There is no clear reason for this difference, but there are anatomical and endocrine differences between the two sexes [14,17]. Some authors [18] have mentioned the differences genetically determined by the neuroendocrinological systems. Rajpoot RS study on the effect of sex hormones on EPI in postmenopausal women noted a decrease in P100 latencies and amplitudes under estrogen and an increase under progesterone [19]. This suggests the involvement of sex hormones in the difference in parameters of EPI in the two sexes.
While several studies show a relationship between EPI and sex $[8,9,12,13,15,16]$, there are however studies in which this relationship has not been observed [20,21]. This lack of relationship between EPI and gender can be explained by the fact that these studies were carried out in the elderly and in children, respectively.

Right eye/Left eye variation

The latencies of the N75, P100 and N145 on the right were slightly higher than those on the left. The majority of the literature $[4,8,10,11]$ has observed this finding.

Variation of P100 parameters as a function of age and anthropometric parameters

In our study, VEP parameters did not vary with age. This finding corroborates the literature $[9,10]$. However, several authors have found a relationship between age and VEP $[8,12,13]$. Thus, in the Celesia study, a considerable increase in the latency of P100 was noted with age [14].

The relationship between VEP and anthropometric parameters (weight, height) was observed but not with BMI in our study. The lack of relationship with BMI has also been observed in the literature [10]. A relationship between latencies of N70, P100 and N155 with weight, BMI and height has been shown in female subjects. But in men, the significant correlation was only found between N145 latency and height [8].

\begin{tabular}{|c|c|c|c|c|c|}
\hline Authors & Kind & $\begin{array}{c}\text { Latencies } \\
\text { N75 }\end{array}$ & $\begin{array}{c}\text { Latencies } \\
\text { P100 }\end{array}$ & $\begin{array}{c}\text { Latencies } \\
\text { N145 }\end{array}$ & Amp P100 \\
\hline NGASSAKI., et al. & Total & $67,98 \pm 4,75$ & $96,25 \pm 4,97$ & $133 \pm 12,36$ & $6,61 \pm 3,28$ \\
\hline Bugème., et al. [10] & Male & $73,35 \pm 5,35$ & $100,91 \pm 4,08$ & $146,22 \pm 8,10$ & $5,64 \pm 1,92$ \\
\hline MonirehMahjoob [4] & Total & $75,21 \pm 4,14$ & $102,42 \pm 5,37$ & $143,68 \pm 8,43$ & $15,04 \pm 6,26$ \\
\hline Ruby Sharma [8] & Male & $66,348 \pm 7,954$ & $93,41 \pm 10,628$ & $150,478 \pm 9,295$ & $5,708 \pm 0,485$ \\
\hline Shibasaki., et al. [12] & Total & $67,8 \pm 4,04$ & $92,44 \pm 4,4$ & $136 \pm 12,11$ & \\
\hline
\end{tabular}

Table 8: Comparison of normal VEP with previous studies.

\section{Conclusion}

VEPs are an important diagnostic tool because they provide information on the functional integrity of the visual pathways; they contribute to the diagnosis of several disorders of the nervous system such as neuromyelitis optic and multiple sclerosis. How- ever, given the variations in equipment and recording conditions, it recommended that each clinical neurophysiology laboratory be able to have its own normative values for VEP. It emerges from this study that our values corroborate those of several authors and that the parameters of VEP vary with respect to sex and anthropometric parameters but not with age and BMI.

Citation: Nagasaki Saurel Ralmach., et al. "Elaboration of Normative Values of Visual Evoked Potentials in the Neurophysiological Exploration Laboratory of the Neurology Department at Fann Teaching Hospital in 2020". Acta Scientific Neurology 4.12 (2021): 51-59. 


\section{Conflict of Interest}

The authors claim not to have any conflict of interest and each author has participated in the development of the document.

\section{Bibliography}

1. Odom J Vernon., et al. "International Society for Clinical Electrophysiology of Vision. ISCEV standard for clinical visual evoked potentials". Documenta Ophthalmologica 133 (2016): 1-9.

2. Adrian ED and Matthews BH. "The interpretation of potential waves in the cortex". The Journal of Physiology 81 (1934): 440471.

3. Rigaudière Florence. "V-5: cortical visual evoked potentials (PEV)". Eye and physiology of vision V-Electrophysiological signals (2013).

4. Monireh Mahjoob., et al. "Normative values of visual evoked potentials in Northeastern of Iran". Journal of Optometry 12 (2019) 192-197.

5. Odom JV., et al. "ISCEV standard for clinical visual evoked potentials". Documenta Ophthalmology 120 (2010): 205-214.

6. Carter JL. In: Clinical Neurophysiology. Edition. Daube JR and Rubin DI. 3rd edition. Oxford University Press. Visual Evoked Potentials (2009): 311-322.

7. McCulloch DL and Skarf B. "Development of the human visual sysstem: monocular and binocular pattern VEP latency". Investigative Ophthalmology and Visual Science 32 (1991): 23722381.

8. Sharma Ruby., et al. "Visual Evoked Potentials: Normative Values and Gender Differences". Journal of Clinical and Diagnostic Research 9.7 (2015): CC12-CC15.

9. Patricia de Freitas Dotto., et al. "Gender-based normative values for pattern-reversal and flash visually evoked potentials under binocular and monocular stimulation in healthy adults". Documenta Ophthalmologica 135.1 (2017): 53-67.

10. Bugeme M., et al. "Visual evoked potentials: Normative values from healthy Senegalese adults". Journal of Neuroscience and Neurological Disorders 4 (2020): 049-052.

11. El Machkourmerieme. "Establishment and development of normal values of visual evoked potentials in the clinical neuro- physiology laboratory of the chu Hassan ii neurology service in fez". Thesis for obtaining the DES neurology (2011).

12. Shibasaki H and Kuroiwa Y. "Pattern reversal visual evoked potentials in Japanese patients with multiple sclerosis". Journal of Neurology, Neurosurgery, and Psychiatry 45.12 (1982): 1139-1143.

13. Tandon OP and Sharma KN. "Visual evoked potential in young adults: a normative study". The Indian Journal of Physiology and Pharmacology 33.4 (1989): 247-249.

14. Celesia GG., et al. "Effects of age and sex on pattern electroretinograms and visual evoked potentials". National Library of Medicine 68.3 (1987): 161-171.

15. Kjaer M. "Visual evoked potentials in normal subjects and patients with multiple sclerosis". Acta Neurologica Scandinavica 1 (1980): 1-13.

16. Dion LA., et al. "Sex differences in visual evoked potentials in school-age children: What is the evidence beyond the checkerboard?" International Journal of Psychophysiology 88.2 (2013): 136-142.

17. Marsh MS and Smith S. "Differences in the pattern visual evoked potential between pregnant and non-pregnant women". Electroencephalography and Clinical Neurophysiology 92 (2014): 102-106.

18. Kaneda Y., et al. "Sex differences in visual evoked potential and electroencephalogram of healthy adults". The Tokushima Journal of Experimental Medicine 43.3-4 (1996): 143-157.

19. Rajpoot RS., et al. "Effect of Hormone Repalcement Therapy on Visual Evoked Potentials in Post-Menopausal Females". International Journal of Medical Research Professionals 1.3 (2015): 24-28.

20. Mitchell KW., et al. "Visual evoked potentials in the older population: age and gender effects". Clinical Physics and Physiological Measurement 8.4 (1987): 317-324.

21. Tandon OP and Ram D. "Visual evoked responses to pattern reversal in children". The Indian Journal of Physiology and Pharmacology 35.3 (1991): 175-179.

\section{Volume 4 Issue 12 December 2021 (C) All rights are reserved by Nagasaki Saurel Ralmach.,} et al. 